Original Research

\title{
Evaluation of Experimental Jugular Thrombophlebitis in Horses Treated With Heparin
}

\author{
Alexandre C. Borghesan ${ }^{a}$, Roberta G. Barbosa ${ }^{a}$, Nereide F. Cerqueira ${ }^{a}$, \\ Regina K. Takahira a , Luiz C. Vulcano a, Ana Liz G. Alves a , Marcos J. Watanabe a, \\ Juliana M. Alonso a, Hamilton A. Rollo ${ }^{\mathrm{b}}$, Carlos A. Hussni ${ }^{\mathrm{a}}{ }^{*}$ \\ ${ }^{a}$ Department of Veterinary Surgery and Anesthesiology, School of Veterinary Medicine and Animal Science, São Paulo State University (Unesp), Botucatu, \\ Brazil \\ b Department of Surgery, Medical School, São Paulo State University (Unesp), Botucatu, Brazil
}

\section{A R T I C L E I N F O}

\section{Article history:}

Received 27 March 2018

Received in revised form

15 June 2018

Accepted 18 June 2018

Available online 25 June 2018

\section{Keywords:}

Activated partial thromboplastin time

Horses

Thrombosis

Ultrasound

Venography

\begin{abstract}
A B S T R A C T
Jugular thrombophlebitis is a major vascular disease in horses and can lead even to death. Heparin is used to inhibit thrombus growth in humans. The aim of this experiment was to evaluate heparin administration in horses with induced thrombophlebitis. Ten animals were subjected to experimental thrombophlebitis and divided into a control group and heparin group (HG). The HG received heparin $(150 \mathrm{IU} / \mathrm{kg})$ for 10 days. Coagulation tests, ultrasound, and venography were performed before and after thrombophlebitis induction. Comparing the HG and control group, a break in the growth of the thrombus after the start of administration of the drug and a decrease in the length of the thrombus with the appearance of flow down the sides of the cranial portion of the thrombus were observed. However, after discontinuation of heparin, fast daily growth of the thrombus and decreased blood flow to the side were observed.
\end{abstract}

(C) 2018 Elsevier Inc. All rights reserved.

\section{Introduction}

Thrombophlebitis is a venous thrombosis secondary to vessel wall inflammation; it most commonly affects jugular veins in horses because these vessels are the most accessed [1]. Jugular thrombophlebitis is one of the most common vascular diseases in horses. It is usually iatrogenic, associated with inadequate venipuncture technique, intravenous injections of irritant drugs [2,3], or improper placement and/or management of indwelling catheters $[4,5]$. Its occurrence is even greater if there is predisposition of the patient, especially in cases of intestinal diseases and endotoxemia [6-9].

\footnotetext{
Animal welfare/ethical statement: This study is in accordance with the Ethical Principles in Animal Experimentation, and it is approved by the Board of Ethics in Animal Experimentation of the Faculty of Veterinary Medicine and Animal Science-UNESP, protocol number 141/2007-CEEA.

Conflict of interest statement: The authors declare no conflict of interests.

* Corresponding author at: Department of Veterinary Surgery and Anesthesiology, School of Veterinary Medicine and Animal Science, São Paulo State University (Unesp), Botucatu, Brazil.

E-mail address: cahussni@fmvz.unesp.br (C.A. Hussni).
}

Medicines that are most frequently associated with thrombophlebitis development are glycerol guaiacolate, thiopental, calcium gluconate, oxytetracycline, and phenylbutazone, a widely used antiinflammatory in athletic horses [1]. Complications of jugular vein thrombophlebitis in horses, whether septic or not, are decreased performance [10] and even death [11-13].

Heparin is an anticoagulant agent that binds to antithrombin III and inhibits fibrin formation [14]. Administration of unfractionated heparin is routinely used in the treatment of jugular thrombophlebitis, and other diseases in horses, however, is often associated with other topical or systemic drugs, including analgesics, antiinflammatory, rheological, vasodilators, platelet inhibitors, and antibiotics [12]. All these drugs may act synergistically with heparin, and its action cannot be reliably assessed. Although some studies showed the anticoagulant action of heparin in healthy horses [15-17], no experimental model demonstrated the effectiveness of heparin disassociated of other drugs in horses.

It is important to evaluate heparin effects in horses because thrombophlebitis has a high prevalence and the drug is a possible tool of preventing disease progression and of minimizing its complications. In this way, the present study aims to evaluate the effects of heparin on experimentally induced jugular thrombophlebitis in 
horses through clinical, laboratorial, ultrasonographic, and venographic evaluations.

\section{Materials and Methods}

This study is in accordance with the Ethical Principles in Animal Experimentation, and it is approved by the Board of Ethics in Animal Experimentation of the Faculty of Veterinary Medicine and Animal Science-UNESP, protocol number 141/2007-CEEA.

Ten healthy adult horses from both sexes were divided into a control group (CG) and a group treated with heparin (Liquemine [5000 IU/mL], Roche Chemical Pharmaceutical Products, São Paulo, SP, Brazil) (heparin group [HG]). Unilateral experimental thrombophlebitis was inducted in accordance with Hussni et al. [18]. The horses were sedated with xylazine hydrochloride (Sedazine, Fort Dodge Animal Health, Campinas, SP, Brazil) (1 mg/kg IV); the middle third of the right jugular area was clipped and anesthetized with lidocaine (Xylestesin, Cristália, Itapira, SP, Brazil); a 10-cm skin incision was made, and the jugular vein was dissected; two DeBakey vascular clamps were applied in the jugular vein, respecting the distance of $5 \mathrm{~cm}$ between them; caudally to the clamps, a temporary ligature with surgical silk (JP, Ribeirão Preto, SP, Brazil) was applied around the vessel and fixed into the skin, to cause stenosis in the caudal part to the thrombus; $50 \%$ glucose (JP) solution was administered in the vein segment in stasis through a $21 \mathrm{G}$ scalp (Plascalp, Feira de Santana, BA, Brazil) until the vessel dilation; after 15 minutes after administration, the clamps were removed, and the subcutaneous was sutured with a continuous cushing pattern using polyglactin 910 (Vicryl; Ethicon, Johnsons \& Johnsons, São José dos Campos, SP, Brazil) and the skin in a simple interrupted pattern using nylon $2-0(\mathrm{JP})$; and the temporary suture placed in the vessel was removed after 3 days.

Heparin $(150 \mathrm{IU} / \mathrm{kg})$ was administered twice a day, subcutaneously to the HG for 10 days. First application was performed at the following day of the removal of the transcutaneous suture, considered the moment of thrombosis induction.

Clinical examinations were performed daily since the preinduction phase until the 18th day. Cephalic region was evaluated by observing the occurrence of edema and vessels engorgement, especially at the masseteric, supraorbital, submandibular, and parotid regions. Edema, local temperature, painful sensitivity to touch, and jugular engorgement at the region of the thrombus and at the cranial and caudal portions of it were observed at the cervical region.

Ultrasonographic evaluations of the right jugular were performed daily since preinduction time until the 18th day after the procedure, using a $7.5 \mathrm{MHz}$ linear transducer B mode (SSD 900 [FAPESP 99/11469-0]; Aloka, Sumpfstrasse, Zug, Switzerland). Presence and regularity of blood flow, preoperative vascular evaluation, and individual characteristics of segments of the thrombi were evaluated from cranial to caudal, in transverse and longitudinal sections of the vessel. Presence of flow and of thrombus, length and characteristics of the thrombus, and venous compressibility under the ultrasound transducer pressure were assessed. The length of the thrombi was statistically analyzed by a nonparametric test for dependent variables (two-way repeated-measures ANOVA), using the mean values for each time.

Venographies were performed in standing position using a portable X-ray (FNX - 90 CTI - Electra Ltda [FAPESP 04/01946-6], Rio de Janeiro, RJ, Brazil). The technique consisted in a left to right projection, with the chassis $(30 \times 40 \mathrm{~cm})$ placed over the right jugular, at 70 kilovolts, 3 milliamps per second, and $90 \mathrm{~cm}$ of distance between chassis and bulb. The used contrast was iohexol (Omnipaque; Sanofi Winthrop Pharmaceutical, São Paulo, SP, Brazil) $(20 \mathrm{~mL})$. Examinations were performed: before induction and at the 6 th, 12 th, and 18 th day after induction. Vascular patency, valves, flow through the thrombus, presence, quantity, characteristics and configuration of collateral vessels, regularity of the venous path, venous gauge and contour, presence or absence of collateral circulation, and the rate of filling or emptying of angiographic contrast in the venous system were evaluated $[13,19]$.

Blood samples from the left jugular were taken in tubes with $3.2 \%$ sodium citrate [20]. Activated partial thromboplastin time (APTT) was achieved from plasma, using commercial kits ("aPTT Reagent with Micronized Kaolin Activator"and "Thromboplastin Reagent"; Helena Laboratories, Lindbergh Dr, Beaumont, EUA). Blood and total platelet counts were processed as routine. APTT and total platelet counts were measured daily since one day before the induction until the 12th day after induction of thrombophlebitis. Blood counts were performed at preinduction times and on the 3rd, 7 th, 10th, and 12th days after induction. APTT, platelet count, and the total cell volume were statistically analyzed by a nonparametric test for dependent variables (two-way repeated-measures ANOVA), using the mean values for each time.

\section{Results}

General physical examination was normal in all animals by both groups. Animals of both groups showed edema in masseteric, supraorbital, submandibular, and parotid regions, with engorgement of the facial transverse vein after induction. Edema was most intense in the first 24 hours after thrombosis induction, gradually regressing and remaining discrete until the end of this period. Cervical examination showed significant decrease of edema by the end of the period. Over the suture line, the jugular was visibly distended, without performing tourniquet. Jugular vein palpation showed stiffening with tubular, firm, and sensitive aspect that did not decline to the compression due to the presence of thrombus. Local sensitivity was discrete in the first 3 days after thrombosis induction.

In the postinduction period, the cephalic edema, which had already lowered at the end of the induction period, continued to regress, becoming almost undetectable in all animals in the CG on the 13th day. In the treated group, the cephalic edema also tended to disappear. However, after discontinuing heparin, on the 10th day after induction, a discrete increase in volume was observed. Masseteric, supraorbital, submandibular, and parotid regions were subtly larger than at the end of the induction period. This new enlargement of the cephalic region also showed gradual reduction, making it almost unnoticeable on the 18th day after induction.

Jugular and adjacent region showed reduction of edema in the surgical area after 5 days of induction. The surgical scar was no longer visible after 13 days. In the CG, there was a tendency toward growth of thrombi near the union of the lingual-facial and maxillary veins, or above them, maintaining the jugular distended firm and unyielding to compression. In the treated group, during the 10 days of treatment, the interruption in the growth of thrombi was observed, which remained palpable at the same area bounded toward the end of the induction period. On the 10th day after the induction, with the end of heparin administration, there was a rapid growth of thrombi, which became palpable in more cranial portions of the jugular, also approaching the junction of the lingualfacial and maxillary veins.

Ultrasonography performed at preinduction time did not show abnormalities in the jugular veins. Without implementation of the tourniquet, the jugular presented with thin echogenic walls, with irregular outline and small anechoic light. By performing the tourniquet at the entrance of the chest, the jugular vein has distended, acquiring circular contour (Figure 1).

Ultrasonography performed in the induction showed thrombus with heterogeneous aspect, with lower echogenicity compared to the blood and surrounding tissues, totally obstructing the vascular 
lumen (Figure 1A). In all animals, on the first day of induction, the distension of the cranial region of the jugular, with turbulence from the maxillary vein, before the junction with the facial-lingual vein, and with flow below the junction becoming more echogenic with tendency to blood stasis near the thrombus, was verified.

On the third day of induction, after removing the silk line that held the stenosis, the thrombi dilated the jugular and did not alter its forward format front of compression with the transducer. The length of thrombi ranged from 15 to $44 \mathrm{~cm}$. Despite the removal of the silk thread, the region of the stenosis did not show blood flow, being completely blocked by the presence of thrombi (Figure 1B).

In control animals, thrombi grew against the direction of blood flow through the jugular, and flow changes in the upper vessels became more evident. On the eighth day, cessation of growth and onset of flow through lateral areas of the cranial portion of the thrombus were observed. From the ninth day after induction, a slight decrease in the length of thrombi along with an increase in the lateral flow area was observed in two animals. In the remaining animals in the CG, there was increase in the lateral flow, without decreasing the length of the thrombi. In the 18th day after induction, all animals showed thrombi with hyperechoic and heterogeneous aspect, with anechoic areas inside and heavy flow on lateral (Figure 1C). The vein showed gradual reduction of the thrombus and of the vessel diameter.

In the treated group, an interruption of the growth of thrombi after the first administration of heparin was observed. In four animals, a slight decrease in the length of the thrombi was observed, with the onset of flow over the sides of its cranial portions, from the sixth day after induction (Figure 1D). Lateral flow without decrease in the length of the thrombus was present in one animal. The thrombus remained with the same extent of the beginning of the treatment until the end of the evaluation. After the discontinuation of heparin, four animals showed fast daily growth of the thrombus with flow decreased. In the 18th day after induction, the animals of the treated group showed thrombi with similar characteristics to those of the CG, that is, hyperechoic and heterogeneous thrombi, with anechoic areas inside and heavy flow on lateral.

Although both groups have different growth patterns of thrombus during the postinduction period, statistical analysis by $\mathrm{F}$ test, performed to compare the mean length of thrombi, showed no significant difference $(P>.05)$ for this feature in the 1st, 10th, and 18 th days, between treated and control groups (Table 1 ).

Venographic examinations before induction of thrombophlebitis, in all animals, demonstrated a thin and continuous line of contrast dissipating through the vein, without accumulation, distension of vessel, or presence of collateral vessels (Figure 2A).

Immediately after the thrombosis induction, the jugular was seen stretched and filled with contrast, with radiopaque aspect in all animals (Figure 2B). The contrast skirted a portion with irregular appearance and accumulated close to the point of stenosis. Only one animal of the CG had a fillet of contrast passed through the stenosis.


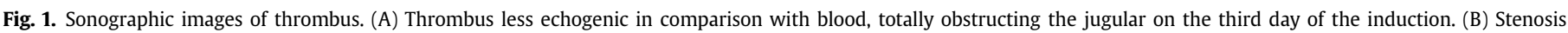



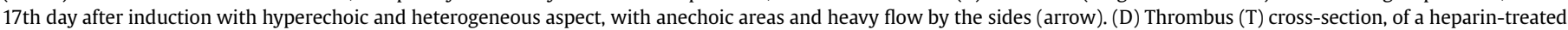
group animal, on the 6th day after induction, with lateral flow (arrow) in the cranial portion of the thrombus. 
Table 1

Mean lengths $(\mathrm{cm})$ of thrombus at 1,10 , and 18 days after induction in each group.

\begin{tabular}{llll}
\hline Group & 1 Day & 10 Days & 18 Days \\
\hline HG & 24.6 & 22.2 & 29.2 \\
CG & 24.8 & 29.4 & 27.8 \\
\hline
\end{tabular}

HG, heparin group; CG, control group.

No statistical difference was observed.

Venographies performed after removing the stenosis (72 hours) showed accumulation of contrast in the cranial portion of the vessel in all animals, indicating the presence of thrombus completely blocking the vein. Animals from both groups showed collateral vessels in the cranial portion of the thrombus, with branching in the caudal direction, making the drainage of contrast. In one animal in the CG and two animals in the treated group, there was the return of the contrast through the lingual-facial vein; however, no animal showed reflux into the maxillary vein.

On the 6th day after induction, the venographic examination in the CG showed that in 3 animals, there was increase in the compensatory vascularization, with collateral vessels draining the contrast from the cranial portion of the thrombus (Figure 2C). In two animals, the compensatory vascular network remained similar to that observed at the end of the induction period; however, passage of the contrast through the side of the cranial and media portion of the thrombus was visualized. In the treated group animals, on the 6th day after induction, three animals showed increase in the compensatory vascular network, with thicker and divided collateral vessels. Two animals showed the development of the small compensatory vascular network, with drainage of contrast through the side of the thrombus to the distal area, near to the stenosis (Figure 2D).
The venographies on the 12th day after induction presented passage of contrast around the thrombus in four CG animals, increasing the flow through the thrombus side. In one animal, the occlusion was total with drainage only by collateral veins. In the HG, one horse showed accumulation of contrast in the cranial region of the thrombus with drainage through compensatory veins and reflow of the contrast through the lingual-facial vein. Two animals presented an intense compensatory vascular network and drainage of all the contrast; and two others, in addition to the compensatory vascular network, presented a small contrast passage through the lateral portions of the thrombus.

In the last venography on day 18 , four CG animals had drainage of contrast through the compensatory collateral vasculature and flow of contrast through the lateral portions of the thrombus. One horse has intense flow of contrast around the thrombus. On the same day, the venographies in treated group animals showed two animals with contrast drainage by the collateral vascular network and small contrast flow through the lateral of the cranial portion of the thrombus. Two animals showed a well-developed compensatory collateral vascular network, draining virtually all the contrast, and one animal had intense contrast flow around the thrombus, allowing drainage through the partially obstructed jugular.

APTT determination during preinduction and induction periods showed normal values, without significant changes for all animals of both groups, as expected. Comparative analysis of the mean of APTT in the preinduction period showed no statistically significant difference between groups. From the first day after induction, after initial administration of heparin, APTT increased significantly until the end of drug administration. Statistical analysis for the APTT showed a significant difference only at day 12 , when heparin


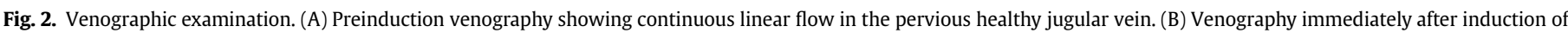

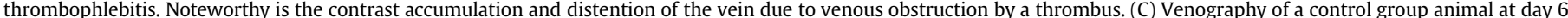

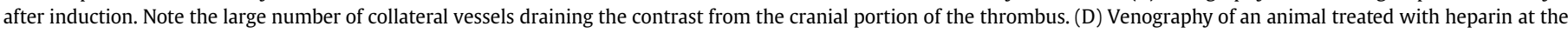
6 th day after induction. Noteworthy is fewer collateral vessels and contrast drainage at the sides of the thrombus. 
Table 2

Comparison of APTT values between the groups.

\begin{tabular}{|c|c|c|c|c|c|c|}
\hline Group & Before Induction & 3 Days After Induction & 7 Days After Induction & 10 Days After Induction & 12 Days After Induction & Mean/Group \\
\hline HG & $49.6 \mathrm{aA}$ & $73.8 \mathrm{aB}$ & $75.4 \mathrm{aB}$ & $71.8 \mathrm{aB}$ & $59.0 \mathrm{aAB}$ & $65.92 \mathrm{a}$ \\
\hline CG & $50.2 \mathrm{aA}$ & $49.6 \mathrm{bA}$ & $49.2 \mathrm{bA}$ & $50.0 \mathrm{bA}$ & $51.4 \mathrm{bA}$ & $50.08 \mathrm{~b}$ \\
\hline Mean/moment & $49.9 \mathrm{~B}$ & $61.7 \mathrm{AB}$ & $62.3 \mathrm{~A}$ & $60.9 \mathrm{AB}$ & $55.2 \mathrm{AB}$ & \\
\hline
\end{tabular}

APTT, activated partial thromboplastin time; HG, heparin group; CG, control group.

Mean values followed by the same lowercase letter in the column and upper case in the row do not differ statistically from each other by the Tukey's test $(P<.05)$.

treatment had already been finished. For APTT values in the CG, statistical analysis showed no significant difference. When comparing the mean values of APTT between control and treated groups in each of the moments, the statistical analysis showed significant difference in $3 \mathrm{rd}, 7$ th, 10 th, and 12 th days after induction (Table 2).

There was no change in the normal range for red blood count, total platelet count, total plasmatic protein, and fibrinogen of the $\mathrm{CG}$, at all times assessed.

Statistical analysis comparing the mean values of packed cell volume of the CG in each of the moments (before induction, 3rd, 7 th, 10th, and 12th days after induction) showed no significant difference. In the treated group, a significant decrease between the value found in the preinduction period and the other moments, which do not differ statistically among them, was observed. However, statistical analysis comparing the mean values of packed cell volume between the CG and the treated group showed a significant difference in those moments (Table 3 ).

The remaining variables (total platelet count, total plasma protein, and fibrinogen) remained within physiological parameters. In the treated group, agglutination of erythrocytes from the 7th day after induction in one animal and from day 10 after induction in two animals was observed. The agglutination of red blood cells did not occur at any time in the CG and was also not observed in the other two animals of the treated group.

\section{Discussion}

The animal assessment by physical examination was within normal parameters in all animals of both groups throughout the experiment. These results were expected and are in agreement with the findings of Hussni et al. [18] and Barbosa et al [21], who obtained similar results when using the same form of experimental jugular thrombophlebitis induction. The maintenance of normal physical parameters shown in the experiment was mainly due to the disease being unilaterally induced and to the pattern of the studied animals (healthy and not carrying diseases that predispose to jugular thrombophlebitis).

Similar to these results, clinical signs of jugular thrombophlebitis in horses are usually only local, being perceived by palpation, engorgement of the affected venous segment, and with pain and increased local temperature. Edema is usually superficial, involving the subcutaneous tissue and skin [7,8,22]. More serious systemic changes may occur more commonly in cases where there is a bilateral thrombophlebitis of the jugular, without a decrease in venous drainage of cephalic region, which causes edema of face, tongue, pharynx, larynx, and parotid region, and dyspnea [12,23-25]. Although rare in horses, the formation of lung abscesses and pneumonia as a result of migration of septic emboli are also related to systemic changes, particularly dyspnea and fever [26,27].

During the induction period, the evaluation of the cephalic region of the animals showed the occurrence of venous engorgement and edema in all animals of both groups. These clinical signs are classically found in horses with jugular thrombophlebitis [23]. The gradual decrease of the edema observed during the experiment can be explained by the compensation of the blood drainage of the cephalic region performed by the remaining jugular because thrombosis was induced unilaterally. In addition, the severity and permanence of changes occurring after venous obstructions are conditioned by the number and size of the collateral vessels and existing anastomosis, which can restore blood flow through a strain with increase in the local pressure [28].

In the CG, during the postinduction, the edema of the cephalic region has receded to become barely noticeable. In these animals, the gradual reduction of edema may also be related to recanalization of the jugular, a fact that could be verified by venography and ultrasonography that showed an increased blood flow around the thrombus.

In the treated group, edema of the cephalic region also tended to disappear during the postinduction. However, after discontinuing the administration of heparin, a slight increase in volume was again observed, making the region larger than at the end of the induction period. The return of edema in these animals is related to the growth of the thrombus, which until then was abolished by heparin. Through venography and ultrasound examinations, it is possible to confirm not only the growth of thrombus but also a decreased blood flow around them.

Identification of thrombi was easily accomplished through the ultrasound examinations during the induction period. The thrombi were presented as a hypoechoic mass within the blood vessel in all animals, as described by Reef [29]. However, very recent thrombi can be difficult to diagnose because its echogenicity is similar to that of blood, and in those cases, the compression technique with the transducer on the stricken vessel helps to distinguish acute thrombi $[29,30]$. The ultrasound with "echo doppler" is also a useful diagnostic tool for the identification of small thrombus or thrombi with the echogenicity similar to that of blood [29].

Monitoring the echogenicity of thrombi in rats and primates showed that it increases with the time evolution of the thrombus, leading to greater accuracy in determining its age [31]. The same was observed during the course of this experiment, where older

Table 3

Comparison of the mean values of globular volume (\%) between the groups.

\begin{tabular}{|c|c|c|c|c|c|c|}
\hline Group & Before Induction & 3 Days After Induction & 7 Days After Induction & 10 Days After Induction & 12 Days After Induction & Mean/Group/Moment \\
\hline HG & $29.0 \mathrm{bB}$ & $22.0 \mathrm{bA}$ & $18.8 \mathrm{bA}$ & $19.8 \mathrm{bA}$ & $22.2 \mathrm{bA}$ & $22.4 \mathrm{~b}$ \\
\hline CG & $35.0 \mathrm{aA}$ & $32.2 \mathrm{aA}$ & $32.2 \mathrm{aA}$ & $32.2 \mathrm{aA}$ & $32.4 \mathrm{aA}$ & $32.8 \mathrm{a}$ \\
\hline Means/Moment/Group & $32.0 \mathrm{~A}$ & $27.1 \mathrm{~B}$ & $25.5 \mathrm{~B}$ & $26.0 \mathrm{~B}$ & $27.3 \mathrm{~B}$ & \\
\hline
\end{tabular}

HG, heparin group; CG, control group.

Mean values followed by the same lowercase letter in the column and upper case in the row do not differ statistically from each other by the Tukey's test $(P<.05)$. 
thrombi started to show hyperechoic and heterogeneous aspect with the presence of anechoic areas inside.

Anechoic cavities in a thrombus are usually associated with a jugular septic thrombophlebitis [32]. During this experiment, the ultrasound monitoring of thrombus in animals from both groups allowed the identification of hypoechoic and anechoic areas within the thrombus, which yielded no compression with the transducer. However, no amendment would suggest the presence of infection or gas production to justify these images, suggesting they are part of the natural evolution of thrombi.

In the present study, although the measurement of the length of the thrombi did not show significant differences between the groups, there was cessation of growth of thrombus during the administration of heparin in the treatment group, whereas the CG showed thrombi with constant growth. This confirms the effect of heparin on limiting thrombus growth [14].

The ultrasound observation of naturally occurring thrombi in human patients suggests that the recanalization starts already after 7 days, with the regression of most thrombi happening within the first 3 months after the incident [33]. In this experiment, all animals in the CG had, by the 8th day after induction, the appearance of areas of flow over the sides of the cranial portion of the thrombus. However, no blood flow and recanalization in the internal areas of thrombus were observed. In the treated group, the flow passage around the thrombus could be seen even earlier, around the 6th day after induction. Furthermore, in four animals of this group, a slight decrease in the size of thrombi was found.

In venography, the thin and continuous line of contrast dissipating through the jugular observed in all animals during the preinduction period, together with the lack of accumulation of contrast, stretching the vessel, and the absence of collateral vessels, characterized the healthiness of the jugular.

Collateral vessels were rapidly opened around the occlusion area, allowing immediate passage of blood from the obstructed end. The opening of compensatory collateral vessels occurred early and could be identified already at the end of the induction phase in all the animals of both groups. However, in other species, drainage flow may remain reduced by up to 1 year after occlusion [34]. Early identification of collateral vessels allows the assumption of preexistence of these vessels, which possibly were opened and started to act due to the pressure change in their drainage areas caused by the jugular obstruction.

The heparin-induced thrombocytopenia reported in humans [35] was not observed. The observed erythrocytes number reduction is as a toxic heparin effect in horses [11,14]. This effect stems from the agglutination of red blood cells because of changes in the membrane or to the stimulation of the production of substances that mediate the interaction between these cells [36].

Duncan et al. [15] attributed the reduction in the number of circulating erythrocytes in horses treated with heparin to the increase in phagocytosis of these cells by macrophages, resulting from the opsonization of erythrocytes by the fibronectin-heparin complex. The phagocytosis of erythrocytes by macrophages may be a hypothesis for the reduction on the cell volume in two animals of the treated group, where the decrease of the cell volume during treatment was less pronounced and no agglutination of red blood cells was observed.

Heparin had controlled the thrombus growth during treatment; however, after discontinuation of treatment, a new growth was observed. Thus, it is important to evaluate the use of heparin in different treatment durations and dosages, preferably, using the low-molecular weight heparin, to seek a strategy that prevents thrombus growth, without thrombus regrowth and minimizing side effects.

\section{Conclusions}

Unfractionated heparin used for treatment of experimentally induced thrombophlebitis in horses promoted restriction of the thrombus growth, and the discontinuation of treatment allowed its regrowth. The efficacy of heparin unassociated with other drugs in cases of jugular thrombophlebitis experimentally induced in horses was demonstrated. Moreover, heparin, in the conditions of the present study, inhibited the growth and facilitated regression of the thrombus. The treatment was efficient to control the induced thrombophlebitis, limiting the growth of the thrombus during its administration. However, regrowth of the thrombus after discontinuation of heparin shows the need for association of heparin with other drugs, with different mechanisms of action on thrombosis in horses.

In spite of thrombus regrowth after treatment discontinuation, these results strengthen the importance of heparin use in thrombus inhibition and subside the need of more studies in horses.

\section{Financial Disclosure}

This work was supported by the grants from CAPES and FUNDUNESP (Grant number 00427-08-UNESP).

\section{References}

[1] Dias DPM, Neto JCL. Jugular thrombophlebitis in horses: a review of fibrinolysis, thrombus formation, and clinical management. Can Vet J 2013;54: 65-71.

[2] Rouleau G, Babkine M, Dubreull P. Factors influencing the development of jugular thrombophlbitis in cattle and comparison of 2 types of catheter. Can Vet J 2003;44:399-404.

[3] Matsuda K, Suzuki H, Tsunoda N, Taniyama H. Jugular thrombophlebitis developed from buccal ulcer in a thoroughbred horse. J Vet Med Sci 2010;72: 913-5.

[4] Müller C, Gehlen H. Catheter-associated complications in the horse - diagnosis and treatment in practice. Tierarztl Prax Ausg G Grosstiere Nutztiere 2016;44: $187-94$.

[5] Lankveld DP, Ensink JM, van Dijk P, Klein WR. Factors influencing the occurrence of thrombophlebitis after post-surgical long-term intravenous catheterization of colic horses: a study of 38 cases. J Vet Med A Physiol Pathol Clin Med 2001;48:545-52.

[6] Morris DD. Thrombophlebitis in horses: the contribution of hemostatic disfuntion to pathogenesis. Contin Educ 1989;11:1386-95.

[7] Traub-Dargatz JL, Dargatz DA. A retrospective study of vein thrombosis in treated with intravenous fluid in a veterinary teaching hospital. J Vet Int Med 1994;8:264-6.

[8] Warmedan EP. "Pseud-catheter-sleeve" sign in the jugular vein of a horse. Vet Radiol Ultrasound 1998;39:148-9.

[9] Dolente BA, Beech J, Lindborg S, Smith G. Evaluation of risk factors for development of catheter-associated jugular thrombophlebitis in horses: 50 cases (1993-1998). J Am Vet Med Assoc 2005;227:1134-41.

[10] Moreau P, Lavoie JP. Evaluation of athletic performance in horses with jugular vein thrombophlebitis: 91 cases (1988-2005). J Am Vet Med Assoc 2009;235: $1073-8$.

[11] Pizzigatti D, Gonçalves DS, Trentin TC, Takahira RK, Alves ALG, Rodrigues CA, Watanabe MJ, Hussni CA. Thromboelastometric evaluation of horses submitted to experimental thrombosis and jugular thrombectomy. Pesq Vet Bras 2016;36:677-86.

[12] Dornbusch PT, Hussni CA, Thomassian A, Alves ALG, Nicoletti JLM. Tromboflebite jugular nos equinos. Rev Educ Contin 2000;3:47-53.

[13] Hussni CA, Barbosa RG, Borguesan AC, Rollo HA. Aspectos clínicos, ultrasonográficos e venográficos da tromboflebite jugular experimental em equinos. Pesq Vet Bra 2012;32:595-600.

[14] Moore BR, Hinchcliff KW. Heparin: a review of its pharmacology and therapeutic use in horses. J Vet Int Med 1994;8:26-35.

[15] Duncan SG, Meyers KM, Reed SM. Reduction of the blood cell mass of horses: toxic effect of heparin anticoagulant therapy. Am J Vet Res 1983;84:2271-6.

[16] Monreal L, Villatoro AJ, Monreal M, Espada Y, Anglés AM, Ruiz-Gopegui R. Comparison of the effects of low-molecular-weight and unfractioned heparin in horses. Am J Vet Res 1995;56:1281-5.

[17] Alonso JM, Rodrigues KA, Yamada ALM, Watanabe MJ, Alves AL, Rodrigues CA Hussni CA. Peritoneal reactivity evaluation in horses subjected to experimental small colon enterotomy and treated with subcutaneous heparin. Vet Med Int 2014;2014:385392. 
[18] Hussni CA, Dornbusch PT, Yoshida WB, Alves ALG, Nicoletti JLM, Mamprim MJ, Vulcano LC. Trombectomia com cateter de Fogarty no tratamento da tromboflebite jugular experimental em equinos. Pesq Vet Bras 2009;29:45-51.

[19] Hussni CA, Dornbusch PT, Alves ALG, Thomassian A, Nicoletti JLM, Cillo GP. Avaliação clínica e angiográfica da vascularização consecutiva à ressecção experimental da jugular de equinos. Vet Zootec 2006;13:163-8.

[20] Lassen ED, Swardson CJ. Hematology and hemostasis in the horse: normal functions and common abnormalities. Vet Clin North Am Equine Pract 1995;11:351-89.

[21] Barbosa RG, Borghesan AC, Cerqueira NF, Hussni CA, Alves ALG, Nicoletti JLM, Fonseca BPA. Fisiopatologia da trombose e tromboflebite da veia jugular de equinos: revisão. Vet Zootec 2009;16:26-37.

[22] McGuirk SM, Shaftoe S, Lunn DP. Moléstias do sistema vascular. In: Smith BP editor. Tratado de MedicinaInterna de GrandesAnimais. São Paulo: Manole; 1993. p. 495-7.

[23] Rijkenhuken ABN, Van Swieten HA. Reconstruction of the jugular vein in horses with post thrombophlebitis stenosis using saphenous vein graft. Equine Vet J 1998;30:236-9.

[24] Young L. Diseases of the heart and vessels. In: Hinchcliff KW, Kaneps AJ, Geor RJ, editors. Equine sports medicine and surgery. London: Elsevier; 2004. p. 728-67.

[25] Russell TM, Kearney C, Pollock PJ. Surgical treatment of septic jugular thrombophlebitis in nine horses. Vet Surg 2010;39:627-30.

[26] Ettlinger JJ, Palmer JE, Benson C. Bacteria found on intravenous catheters removed from horses. Vet Res 1992;130:248-9.

[27] Danetz JS, McLafferty RB, Ayerdi J, Gruneiro LA, Ramsey DE, Hodgson KJ. Selective venography versus nonselective venography before vena cava filter placement: evidence for more, not less. J Vasc Surg 2003;38:928-34.
[28] Maffei FHA, Rollo HA, Lastoria S. Trombose venosa profunda dos membros inferiores: tratamento clínico. In: Maffei FHA, Lastoria S, Yoshida WB, Rollo HA, editors. Doenças vasculares periféricas. 3rd ed. Rio de Janeiro: MEDSI editora Médica e Científica; 2002. p. 1407-26.

[29] Reef VB. Equine diagnostic ultrasound. Philadelphia, USA: W.B. Saunders Company; 1998.

[30] Raghavendra BN, Horii SC, Hilton S, Subramanyam BR, Rosen RJ, Lam S. Deep venous thrombosis: detection by probe compression of veins. J Ultrasound Med 1986:5:89-95.

[31] Fowlkes JB, Strieter RM, Downing LJ, Brown SL, Saluja A, Salles-Cunha S, Kadell AM, Wrobleski SK, Wakefield TW. Ultrasound echogenicity in experimental venous thrombosis. Ultrasound Med Biol 1998;24: $1175-82$.

[32] Jesty SA, Reef VB. Septicemia and cardiovascular infections in horses. Vet Clin North Am Equine Pract 2006;22:481-95.

[33] Meissner $\mathrm{MH}$, Wakefield TW, Ascher E, Caprini JA, Comerota AJ, Eklof B, Gillespie DL, Greenfield LJ, Ruth A, Henke PK, Hingorani A, Hull RD, Kessler CM, Mcbane RD, Mclafferty R. Acute venous disease: venous thrombosis and venous trauma. J Vasc Surg 2007;46:25-53.

[34] Killewich LA, Bedford GR, Beach KW. Spontaneous lysis of deep venous thrombi: rate and outcome. J Vasc Surg 1989;9:89-97.

[35] Tollefsen DM, Zhang L. Heparin and vascular proteoglycans. In: Colman RW, Marder VJ, Clowes AW, editors. Hemostasis and thrombosis - basics principles and clinical practice. 5th ed. Philadelphia: Leppincott Willians \& Wilkins; 2006. p. 217-83.

[36] Moore JN, Mahaffey EA, Zboran M. Heparin-induced agglutination of erythrocytes in horses. Am J Vet Res 1987;48:68-71. 